\title{
Internet Addiction a Comparative Study between Undergraduate Students of India and Malaysia
}

\author{
Dr. Ramyashilpa. D. Nayak ${ }^{1}$
}

\section{ABSTRACT}

Modern day life is truing towards more and more devices and internet fever is just spreading like wild fire. For young people the life is just meaningless without internet, for some it's just like oxygen without which it's impossible for them to survive. According to the researches that have been carried out few years back Internet addiction is a psychological disorder proposed for inclusion in DSM-V (the American Psychiatric Association's Diagnostic and Statistical Manual of Mental Disorders, fifth revision), which was scheduled for publication in 2011. Korean researchers are developing a standard psychological tool called the K-scale to diagnose Internet addiction and measure its severity. According to Dr. Jerald Block, who recommends Internet addiction for inclusion in the manual, the proposed disorder exhibits four common characteristics of addiction: Excessive use, which may be accompanied by impaired sense of the passage of time and/or neglecting basic drives (such as hunger or the need for sleep).Withdrawal (when prevented from going online), which may be manifested as anger, tension or depression, Tolerance which in the case of internet addiction may be indicated by longer use or a perceived need for upgrades or new software. Negative consequences to the behavior, which may include arguments, fatigue, problems at school or work, lying, lack of achievement and social isolation. According to research from Stanford University School of Medicine in Silicon Valley in 2006one in eight people in the U.S. is addicted to the Internet. The typical Internet addict is "a single, college-educated, white male in his 30s, who spends approximately 30 hours a week on non-essential computer use." 14 percent of study respondents had difficulty abstaining for several days. 5.9 percent admitted that their Internet use impacted their relationships. 8.2 percent admitted that they used the Internet to escape reality. 3.7 percent were preoccupied by thoughts of going online when offline. In the present research an effort is made to understand the addiction effect among undergraduate students of India and Malaysia. The objective in the present research is to provide better intervention to the students if any students have high level of internet addiction. It has been hypothesized that compared to Indian students Malaysian students will significantly have high Internet addiction than Indian students. To assess the level of internet addiction among the undergraduate students Internet Addiction Test (IAT) by Dr. Kimberly Youngis used. The sample for the research has been chosen from USM-KLE International Medical College Belagavi and KLE Institute of Nursing Sciences Belagavi. The total sample includes 200 undergraduate students from India and Malaysia (100-Indian students and 100 Malaysian students' male and female); the age of the students is between 18 to 23 years.

Keywords: Internet Addiction, Students, India, Malaysia

\footnotetext{
${ }^{1}$ Lecturer/Coordinator Mentorship Programme USM-KLE Belagavi, Psychiatry Department, USM-KLE Nehru Nagar, Belagavi, Karnataka India

(C) 2015 I R Nayak; licensee IJIP. This is an Open Access Research distributed under the terms of the Creative Commons Attribution License (http://creativecommons.org/licenses/by/2.0), which permits unrestricted use, distribution, and reproduction in any Medium, provided the original work is properly cited.
} 
In the present internet world no person want to know who won the race whether a tortoise or rabbit, everyone wants to search and get the information they want as fast as they can. And in trying to move very fast people forget that they are forgetting to maintain relationships with the people who are present in front of them and trying to gain contact with very remote people and have become very busy in making new friends and relationships whom in reality they don't even know who those people. Of course technology is helpful for the person to communicate with the people and reach to information that cannot be made available at one place. But, people especially the younger generation are becoming addicted to internet and they are not even realizing that how internet is affecting their mental and physical health; research studies conducted few years back also quote that how people are developing various mental illnesses such as depression, anxiety, stress, irritation etc.

Internet addiction is well-defined as any online-related, compulsive behavior which interferes with normal living and causes severe stress on family, friends, loved ones, and one's work environment. Internet addiction has been called Internet reliance and Internet compulsivity. It is a compulsive behavior that completely dominates the addict's life. Internet addicts make the Internet a more significant than family, friends, and work. The Internet becomes the establishing principle of addicts' lives.

No solitary behavior pattern defines Internet addiction. These behaviors, when they have taken control of addicts' lives and become uncontrollable, include: compulsive use of the Internet, a preoccupation with being online, lying or hiding the extent or nature of your online behavior, and an inability to control or curb your online behavior. If your Internet use pattern interferes with your life in any way shape or form, (e.g. does it impact your work, family life, relationships, school, etc.) you may have a problem.

In addition, if you find that you are using the Internet as a means to frequently change your mood you may be rising a problem. It is important to note that it is not the actual time spent online that determines if you have a problem, but rather how that time you spend impacts your life.

Internet addiction can be understood by comparing it to other types of addictions. Individuals addicted to alcohol or other drugs, for example, develop a relationship with their "chemical(s) of choice" - a relationship that takes superiority over any and all other features of their lives. Addicts find they need drugs purely to feel normal. In Internet addiction, a parallel situation exists. The Internet — like food or drugs in other addictions — provides the "high" and addicts become dependent on this cyberspace high to feel normal. They substitute unhealthy relationships for healthy ones. They elect for momentary pleasure rather than the deeper qualities of "normal" friendly relationships. Internet addiction follows the same liberal nature of other addictions. Internet addicts fight to control their behaviors, and experience anguish over their continuous failure to do so. Their loss of self-esteem grows, powering the need to escape even further into their addictive behaviors. A sense of powerlessness pervades the lives of addicts. 
The research study conducted by Kanwal Nalwa, Archana Preet Anand Punjabi University, Patiala, India (2004) showed that significant behavioral and functional usage differences were revealed between the two groups. Dependents were found to delay other work to spend time online, lose sleep due to late-night logons, and feel life would be boring without the Internet. The hours spent on the Internet by dependents were greater than those of non-dependents. On the loneliness measure, significant differences were found between the two groups, with the dependents scoring higher than the non-dependents.

Li Yajun, Zhang Xinghui, Lu Furong, Zhang Qin, and Wang Yun conducted a study on internet addiction and found that considering the location and purpose of Internet use, the percentage of Internet addicts was highest in adolescents typically surfing in Internet cafes (18.1\%) and playing Internet games (22.5\%).

A research conducted by PriyankaYadav, Girish Banwari correspondence email, Chirag Parmar, Rajesh Maniar (2013) reveled that sixty-five (11.8\%) students had Internet Addiction; it was predicted by time spent online, usage of social networking sites and chat rooms, and also by presence of anxiety and stress. Age, gender and self-rated academic performance did not predict Internet Addiction. There was a strong positive correlation between Internet Addiction; and depression, anxiety and stress.

\section{METHODOLOGY}

\section{Aim:}

To develop awareness about Internet Addiction Disorder among the younger generation and provide an intervention of cognitive behaviour therapy of those found with Internet addiction Disorder.

\section{Purpose:}

To make young generation cognize about the Internet Addiction and how it is distressing their mental health through the development of depression, stress, anxiety, loss of self-control, emotional instability, etc.

\section{Objective:}

To find out the level of internet addiction among young student population of India and Malaysia.

\section{Hypothesis:}

It has been hypothesized that Malaysian students will experience more amount of internet addiction than Indian students. 


\section{Sample:}

The sample for the present study for Malaysian students has been chosen from USM-KLE International Medical Programme, students perceiving Medical Education in India through Malaysian Medical Programme. And on the other hand the sample of Indian students has been chosen form KLE Institute of Nursing Sciences Belagavi. All the students are undergoing Undergraduate Programme. The total sample includes 200 students both male and female. 100 among them are Malaysians and 100 are Indian students.

\section{Assessment Tool:}

For the present research the Internet Addiction Test (IAT) developed by Dr. Kimberly Young has been chosen. Internet Addiction Test (IAT) is a reliable and valid measure of addictive use of Internet, developed by Dr. Kimberly Young. It consists of 20 items that measures mild, moderate and severe level of Internet Addiction.

\section{RESULTS AND DISCUSSION}

Table No.1 showing the ' $t$ ' and 'P-value of Indian and Malaysian students with respect to Internet Addiction

\begin{tabular}{|l|l|l|l|l|l|}
\hline Group & $\mathbf{n}$ & Mean & SD & t-value & P-value \\
\hline Indian & 100 & 29.40 & 18.18 & -3.2600 & $\mathbf{0 . 0 0 1 3}$ \\
\cline { 1 - 4 } Malaysian & 100 & 37.62 & 17.47 & & \\
\hline
\end{tabular}

\section{DISCUSSION}

In above table the obtained t-value is -3.26 and p-value is 0.0013 which clearly indicates that the scores are highly significant at ${ }^{*} p<0.05$ level of significance. The results here indicate that compared to Indian group of students Malaysian students are highly addicted towards internet. As Indian students are not still much exposed to internet and also still in some places internet facility is not provided to all the students and also most of the students do not have their own laptops, tablets or smart phones they might have shown less level of internet addiction. But sure that if they are also provided and given more and better opportunities the level of addiction will be same. And there is not much significant difference found between male and female students among both Indian and Malaysian students.

\section{CONCLUSION}

The present study was carried out to find out the level of Internet addiction among both Indian and Malaysian students. And in conclusion it can be said that Malaysian students are more addicted towards the internet than Indian students.

The hypothesis "Malaysian students will experience more amount of internet addiction than Indian students" has been accepted. 


\section{SIGNIFICANCE OF THE STUDY}

The present study was carried out to find out the level of internet addiction among the young generation. Even though the scores indicate less addiction among the Indian students than Malaysian it can be proved that if further research is done most of the young generation are more and more attracted towards the gadgets and internet. But one thing the young people are not realizing is that unknowingly they are becoming addicted to the internet and also they do not know how it is affecting their mental and physical health.

Many research studies have also proved that internet is causing people to be more likely to develop depression and anxiety disorders and also increase in level of aggression. Hence it is important for us to do further research in this field so that better intervention can be provided to the internet addicted people. The intervention may be biofeedback techniques and also behaviour modification techniques. Of course Internet has both advantages and disadvantages but people must be made realize this have they are getting affected by internet unintentionally.

\section{REFERENCE}

Kanwal Nalwa and Archana Preet Anand. (2003)Cyber Psychology \& Behavior Internet Addiction in Students: A Cause of Concern Volume: 6 Issue 6: July 5, 2004

Li Yajun, Zhang Xinghui, Lu Furong, Zhang Qin, and Wang Yun.(2014) Cyber psychology, Behavior, and Social Networking Internet Addiction Among Elementary and Middle School Students in China: A Nationally Representative Sample Study Volume: 17 Issue 2: February 10, 2014

Priyanka Yadav, Girish Banwari, Chirag Parmar, Rajesh Maniar(2013)Internet addiction and its correlates among high school students: A preliminary study from Ahmedabad, India Asian journal of Psychiatry Volume 6, Issue 6, Pages 500-505 